Área Abierta. Revista de comunicación audiovisual y publicitaria

ISSN: 2530-7592 / ISSNe: 1578-8393

\title{
El cine histórico en el ámbito educativo: discursos culturales ante el encuentro con América
}

\author{
Gemma Muñoz García ${ }^{1}$ y Esther Jiménez Pablo²
}

Recibido: 30 de diciembre de 2020 / Aceptado: 25 de enero de 2021 / Publicado: 26 de febrero 2021

Resumen. Este artículo explora las posibilidades que ofrece el cine como recurso didáctico para el análisis de temas polémicos en la enseñanza de la Historia, como es el caso del encuentro cultural entre el Viejo y Nuevo Mundo, a partir de 1492. La recreación de este hecho en el cine permite mejorar, en Primaria, y más aún, en Secundaria y Bachillerato, las competencias cívicas, así como el pensamiento crítico y creativo. Recurriendo a una metodología sistemática de visualización de gran parte de la producción cinematográfica que recrea este episodio histórico, con el análisis de escenas concretas, se ha llegado a caracterizar el tratamiento de la figura del conquistador y del nativo amerindio en el cine, a través del uso de estereotipos prefijados en el imaginario colectivo, tanto en España, como en los países hispanoamericanos principalmente.

Palabras clave: Encuentro; América; Cine Histórico; Educación; Indígenas; Conquistadores

\section{[en] Historical Film in the Educational Field: Cultural Discourses Before the Encounter with America}

\begin{abstract}
This paper explores the possibilities offered by film as a didactic resource for the analysis of controversial topics in the teaching of History, such as the cultural encounter between the Old and New World, from 1492 onwards. Film allows to improve civic, creative and critical thinking skills in Primary/Secondary Education and Baccalaureate. Using a systematic viewing methodology for a large part of the cinematographic production that recreates this historical period, with analysis of specific scenes, we have focused on the treatment of the figure of the conqueror and the native Amerindian in the cinema. All this, through the use of stereotypes in the collective imaginary, both in Spain as in Spanish-American countries, and in foreigners.
\end{abstract}

Key words: Encounter; America; Historical Film; Education; Indigenous; Conqueror

Sumario. 1. Introducción. El cine histórico en el currículo escolar. 2. La relevancia del encuentro entre dos mundos: una recreación complicada en educación y en el cine. 3. Metodología y muestra. 4. Análisis. 5. Conclusión. 6. Bibliografía.

\footnotetext{
1 Fundación IES Abroad Madrid (España)

E-mail: gemma_mmg@hotmail.com

ORCID: https://orcid.org/0000-0002-0406-2634

2 Universidad Complutense de Madrid (España)

E-mail: ejimenezpablo@ucm.es

ORCID: https://orcid.org/0000-0002-1658-7024
} 
Cómo citar. Muñoz García, Gemma y Jiménez Pablo, Esther (2021). El cine histórico en el ámbito educativo: discursos culturales ante el encuentro con América. Área Abierta. Revista de comunicación audiovisual y publicitaria 21 (1), 9-24, https://dx.doi.org/10.5209/arab.73277

\section{Introducción. El cine histórico en el currículo escolar ${ }^{3}$}

Nuestra comprensión de la realidad se construye a través de la imagen que nos formamos de los aprendizajes que adquirimos. Así, la historia del mundo actual sería incomprensible sin los medios y técnicas audiovisuales que muestran distintas perspectivas de la realidad. Entre ellas, el cine ocupa un lugar privilegiado por ser un sistema de comunicación y un vehículo de expresión artística.

Pero qué ocurre cuando queremos acercar aspectos del pasado desde una perspectiva histórica y social en las aulas de Educación Primaria, Secundaria -en adelante, ESO- y Bachillerato. Generalmente acudimos a fuentes textuales, propias de la disciplina histórica, y rescatamos, desde la Historia del Arte, grabados, pinturas, esculturas, fotografías y otras técnicas que nos ayudan a conocer hechos y personajes de otras épocas. Estos son mostrados como deseaba el autor, con las modas de la época, y los intereses de los comitentes de las obras. De manera que la realidad, en el ámbito de lo social, es en buena parte susceptible de ser interpretada. Este hecho no invalida el proceso riguroso de reconstrucción del pasado histórico, si bien nos permite entender la fuente como un recurso influenciado por la sociedad que la produjo, obligándonos a una labor de contrastación de fuentes; por ello, el cine es un recurso más que podemos emplear en el ámbito educativo y que se convierte en un recurso eficaz sobre el que trabajar contenidos históricos en el aula.

Actualmente la enseñanza de la Historia en las aulas es un reto docente. La forma en la que los contenidos son presentados no favorece una enseñanza alejada de modelos tradicionales: el currículo de Educación Primaria vigente en la Comunidad de Madrid, afectando a niños de edades comprendidas entre los seis y los doce años, afirma que éstos no deben analizar y juzgar hechos históricos, sino ser capaces de adquirir un marco referencial espacio-temporal como base para cursos superiores (Decreto 89/2014, p. 20).

El problema es que la enseñanza de la Historia en este momento madurativo se reduce a un mero aprendizaje memorístico que resulta insuficiente para generar un aprendizaje significativo. El propio marco de aprendizaje por competencias que contempla la ley educativa (Ley Orgánica 8/2013) resultado de las recomendaciones del Parlamento y el Consejo Europeo (2006/962/CE) fomenta todo lo contrario, deviniendo en cierta contradicción con el currículo. Así, las competencias vinculadas al conocimiento de lo social -conciencia y expresiones culturales y competencias sociales y cívicas-, promueven por el contrario el espíritu crítico, con una actitud respetuosa hacia las diferentes manifestaciones culturales. Persiguen fomentar la

\footnotetext{
Proyecto COMPROP (PGC2018-094491-B-C31: Emotional dimension and controversial issues in teacher training; PGC2018-094491-B-C33: Methodological concepts and active learning methods to improve the teaching skills of teachers; MASOPA-CM, Ref. H2019/HUM-5898, Madrid, sociedad y patrimonio: pasado y turismo cultural; y PID-UCM, Ref. 103/2021: Observatorio de Historia: recursos didácticos para recuperar la memoria de individuos y sociedades invisibilizadas.
} 
iniciativa, imaginación y creatividad, asumiendo su dinamismo y complejidad, a fin de interpretar los problemas sociales actuales en la línea propuesta por Santisteban (2019).

El pensamiento crítico, reflexivo y la conciencia social deben entrenarse: si queremos que nuestros jóvenes alcancen una madurez crítica para saber tomar decisiones, afrontar problemas sociales complejos, y desarrollar actitudes resilientes, debemos actuar desde etapas tempranas. El cine es un recurso extraordinario para ello. Sin embargo, su uso no ha sido suficientemente explorado desde la enseñanza de las Ciencias Sociales, esencialmente por el papel que representa en el currículo.

En Educación Primaria dos aspectos son preocupantes. El primero, la nula presencia del cine en la asignatura de Historia; y el segundo, que su escasa presencia en otras materias se circunscribe a los estándares de aprendizaje que el alumnado debe alcanzar, y no a los contenidos que debe aprender. Esto relega el uso del cine en esta etapa a un recurso marginal. Ello, unido a factores como el encorsetamiento del maestro al cumplimiento de un vastísimo temario, el tiempo necesario para visionar una película (al menos dos sesiones de clase), y la necesidad de una selección exhaustiva por parte del docente, dificultan el empleo del cine en el aula.

En la etapa de ESO y Bachillerato, su presencia es destacada en tres materias: Cultura Audiovisual, Fundamentos del Arte e Historia del Arte. En todas ellas su presencia queda constatada en contenidos, criterios de evaluación y estándares de aprendizaje. Es un fin en sí mismo desde el punto de vista técnico, narrativo, desde su vinculación con el sonido -bandas sonoras-, y como industria a través de su evolución histórica. Sin embargo, no tiene presencia en la enseñanza de la Historia. Seguramente esto se deba a la posición enfrentada entre historiadores que defienden o rechazan su uso/validez como fuente histórica. Los detractores del cine histórico ponen de relieve los errores que se aprecian en estas proyecciones. Sin embargo, Ferro (1995: 40) considera que estos fallos se constituyen en "agentes reveladores [...] que nos ayudan a descubrir lo latente bajo lo aparente". Porque a una película que presenta algún capítulo del pasado histórico, debemos pedirle verosimilitud más que veracidad, reconociéndose mutuamente tanto el cine como la historia (Martínez, 2013). Es un hecho que el cine está supeditado a intereses comerciales, sociales, modas y críticas. Pero ya hemos visto que no se encuentran en una situación muy distinta las fuentes textuales.

El cine en sí mismo es una experiencia de conocimiento, cuyo uso reporta beneficios en el aula por su fuerza visual y la sensación de realismo e inmediatez que confiere. Diversos autores lo han considerado un testimonio histórico (Ferro, 1980; Burke, 2001). Además, está el factor motivador que fomenta el sentido crítico (Martínez, 2013: 362), reforzado por la utilización del cine como herramienta propagandística e ideológica. Por ello, es necesario aprender a mirar el cine como una manifestación artística de manera reflexiva y crítica, objetivando sus mensajes y valores sociales (Gorgues, Enguix y Goberna, 1997). Su acercamiento a hechos históricos genera además una experiencia evocadora, que permite al espectador reconocerse (Solá y Selva, 1997).

A mediados de los noventa, Rosenstone (1995) señalaba que el cine histórico comenzaba a ocupar un lugar relevante al explorar el significado que cada sociedad proyectaba sobre su pasado. El cine no reemplaza la historia escrita, sino que sería algo "adyacente", al igual que otras formas de abordar el pasado como la memoria y la tradición oral. En esta línea, Pierre Sorlin (2008) considera al cine un recurso 
auxiliar que, sin reemplazar al texto escrito, fuerza al historiador a repensar sobre la idea de cambio en la historia. Para Sorlin, los historiadores no han simpatizado con el cine porque la historia se ha entendido conforme a categorías estáticas como la cronología, contradiciendo la idea de cambio que sí proyecta el cine.

El cine histórico representa una fuente inagotable de contenidos que pueden ser analizados desde distintas ópticas. Un ejemplo es el que será objeto de análisis en este trabajo, el encuentro entre dos mundos a través del descubrimiento, a ojos españoles de un nuevo continente, América. Sobre este nuevo espacio geográfico, el español, a través de conquistadores, exploradores y clérigos, proyectó imágenes sobre su reciente tradición medieval, atribuyendo características de una realidad que se oponía al orden y a la moral europea. Todo el imaginario que se fraguó sobre el nuevo espacio y sus gentes ${ }^{4}$, eran comparadas bajo el prisma del mundo europeo, lo que originó una imagen distorsionada, eurocéntrica y finalmente estereotipada del indígena americano.

Perseguimos con este trabajo los siguientes objetivos: por una parte, constatar el potencial del uso del cine histórico para el conocimiento de la Historia en la ESO y Bachillerato, iniciando una deseable primera aproximación desde Primaria; mostrar la capacidad del recurso fílmico para afianzar o cuestionar aprendizajes previos basados en fuentes textuales, iconográficas u objetuales. Con el uso del cine, además, buscamos acercar al alumnado a aspectos controvertidos e invisibilizados por la historiografía convencional, atendiendo a distintas visiones de la realidad, con el fin de fomentar el pensamiento crítico, reflexivo, analítico y analógico, a través del concepto de empatía histórica (Doñate y Ferrete, 2019).No debemos perder la perspectiva que el cine histórico ha presentado gestas individuales de personajes mitificados, relegando a un segundo plano el protagonismo colectivo de los procesos sociales (Sánchez Noriega, 2008). Estos son a los que buscamos dar relevancia en este trabajo, con el fin de favorecer la reflexión en el ámbito educativo sobre valores cívicos.

\section{La relevancia del encuentro entre dos mundos: una recreación complicada en educación y en el cine}

La llegada de Colón a América cambió la visión del mundo: el Nuevo Mundo significó para Europa una naturaleza insólita, nuevas fuentes de recursos, y la presencia de individuos con otras formas de vida; para América el encuentro con el Viejo Mundo vino cargado de una aculturación polémica, que todavía hoy, parece no resuelta (Laguna, 2011). Paradójicamente, este hecho fundamental no goza de importancia para el currículo escolar, ni los manuales de texto de colegios e institutos españoles dedican demasiadas páginas a su estudio. La falta de profundidad en este tema posiblemente se deba a la polémica en torno a cómo se llevó a cabo la conquista que desvaneció un hipotético proceso de intercambio igualitario. Es una realidad, aceptada por la historiografía, que los soldados transmitieron enfermedades mortales a los nativos y que el oro despertó la avaricia en los conquistadores; un metal que para los

4 Atribuiremos a las sociedades originarias de América los términos: “indígenas, nativos o indios" para no redundar en un mismo vocablo, conscientes de que es más apropiado “indígenas” para el caso de Latinoamérica. 
indios tenía un valor simbólico y sobrenatural, pero para los españoles significaba lujo, riqueza y poder (Mora, 2014).

A lo que hay que añadir toda la propaganda ideológica entorno a la Leyenda Negra, crítica con la actuación de los conquistadores que arrasaron a poblaciones indígenas, y que cabe recordar que fue difundida en la Edad Moderna por la Monarquía inglesa, enemiga acérrima de la Monarquía hispana. Hoy sabemos que la Leyenda Negra tiene parte de realidad, pero también de exageración. Llevar todos estos matices a las aulas es delicado, y puede generar alguna situación desagradable ante la diversidad cultural presente hoy en nuestras aulas, con el riesgo de provocar una falta de entendimiento porque parte del alumnado sienta mayor empatía histórica por los nativos y otros por los conquistadores (España, 1992).

Por eso los docentes deben buscar recursos didácticos que les permitan reflexionar con los estudiantes, sin temor a plantear lo que estuvo bien y mal de aquel encuentro, y todo lo que se ha generado después de este hecho. De manera quelas películas sobre la llegada de Colón y la conquista son recursos necesarios en las aulas porque muestran sin tapujos, y desde perspectivas muy distintas, cuestiones éticas derivadas de ese encuentro, con unos valores desde el presente, que conectan con la realidad del estudiante. El propio cine español ha fluctuado con la imagen de la llegada de los españoles a América: desde la propaganda franquista en el cine imperial de los años cuarenta (García Fernández, 2011: 248), a las visiones más críticas como la de Icíar Bollaín en También la lluvia (2010).

Ahora bien, si esto ocurre en España, en los países hispanoamericanos sucede algo muy distinto; su historia comienza a ser estudiada en profundidad desde el momento en que rompen con el colonialismo español y consiguen la independencia (Pérez Vejo, 2016). Así, el cine hispanoamericano se ha focalizado más en procesos históricos de épocas más recientes que reivindican un discurso nacionalista frente a lo español. Las pocas películas hispanoamericanas sobre el encuentro son, en su mayoría, mexicanas, que reivindican el indigenismo, y evocan un supuesto estado de libertad y felicidad previo a la llegada de los españoles (Mora, 2004).

En otro sentido, las películas sobre el encuentro, además de entretener y educar, buscan reforzar identidades, convirtiéndose en reflejo social, recreando el pasado, comparando el presente, tomando como base las costumbres y valores de uno o varios grupos sociales (Ferro, 1995). Es una ventana intercultural, permitiendo al espectador identificarse y conocer culturas lejanas o desaparecidas; más aún, el cine sobre el encuentro entre Europa y América orienta ideales y denuncia problemas. Es, en definitiva, un instrumento más para interpretar la Historia, que en ocasiones trata de establecer vínculos con el presente de su estreno cinematográfico a través de reconocer cierta continuidad con el pasado, o marcar una abrupta ruptura a modo de denuncia.

Es interesante analizar en las aulas, a través del cine, cómo se trató de integrar a América en la construcción identitaria europea, y la improvisación de los españoles a la hora de penetrar, sin ningún plan concebido, pero con ideas preconcebidas sobre la barbarie caníbal y la exagerada abundancia de oro en cada rincón de selva, que aparecía en la literatura de los cronistas de Indias (López Lizarazo, 2010). Y esto trajo consecuencias, abusos, sometimientos, imposiciones de fe y de cultura, en un intento por hacer de América una extensión de Europa.

Existe además una complejidad añadida; un mismo largometraje admite un abanico de reacciones, influyendo de forma distinta dependiendo de la audiencia que lo 
consuma (López Lizarazo, 2010). Por eso, para que el cine sea utilizado en educación se debe contextualizar el periodo histórico en el que se realizó el largometraje, porque, aunque sean películas sobre el descubrimiento o conquista de América, la ideología del director, del estado o entidad que financie la película, puede influir a la hora de mostrarla propia narración de la historia.

La mayoría de las películas que tratan el tema del encuentro con el nuevo continente son producciones a nivel nacional. Y esto significa también que su propio imaginario nacional queda reflejado (Bueno, 2019), como es el caso por ejemplo del franquismo y su alabanza a los Reyes Católicos y a Cristóbal Colón a través de la filmografía colombina (Pérez Cipitria, 2010). Las películas sobre este tema durante el régimen dictatorial presentaban un carácter épico, de aprendizaje de los grandes héroes, siendo los guiones en muchos casos obra del gobierno, como ocurrió aparentemente con Alba de América (1951) atribuida a Carrero Blanco (Juan-Navarro, 2008). Como indica Luis Deltell, "tal vez uno de los mejores elementos de los que disponen los investigadores para entender lo que fue el franquismo se encuentra en las películas del género histórico del cine español" (Deltell, 2006: 52). Así, en estos filmes buscaban exaltar una corona hispana triunfante que llevó la civilización a las Indias Occidentales, así como la salvación a través de la predicación de la palabra, haciendo un símil con la política franquista basada en la expansión de una misma fe, una misma lengua y un ideal de continuidad de la obra de los Reyes Católicos (España, 1992: 3).

En este trabajo no hemos encontrado películas sobre el siglo XVI en América que sean coproducciones hispanoamericanas y españolas; y esto refleja la falta de consenso a la hora de interpretar qué pasó realmente durante la conquista. Ahora bien, se dieron coyunturas como el V Centenario de 1992, con subvenciones al cine de esta temática, que permitió nuevas reformulaciones sobre la llegada de Colón y la conquista de América, pero siendo la mayoría de estas películas de nacionalidad extranjera, de habla no hispana, que quisieron dar forma a otras imágenes de los conquistadores hasta ese momento no exploradas (Manzi, 2006).Aquí destacaremos una película inglesa sin ningún rigor histórico, la parodia La loca pandilla de Chris Columbus (Carry on Columbus, Gerald Thomas, 1992), en la que Jim Dale encarna al descubridor, y en la que resulta interesante analizar la imagen tipificada de los nativos y de los conquistadores, siendo los españoles muy simples y tontos que regalan a los nativos una muñeca sevillana y un toro, que representaría lo que es España, y los indígenas, a cambio, regalaron a los españoles puros cubanos. Interesante también la imagen tan distinta de Colón en dos películas extranjeras rodadas durante el V Centenario: Cristóbal Colón: el descubrimiento(Christopher Columbus: The Discovery, John Glen, 1992) que contó con ayuda del organismo estatal español del V Centenario y la película 1492: La conquista del Paraíso (1492: The Conquest of Paradise, Ridley Scott, 1992) que contó con el patrocinio del Ministerio de Cultura español. Ambas, muestran a dos Cristóbal Colón que no parecen la misma figura histórica, el de Ridley Scott es más maduro, idílico y ético que el de John Glen, un apuesto galán aventurero (Burman, 2006). Eso sí, ambas películas apuestan por unos soldados ignorantes, ambiciosos y destructores que representarían a la España de entonces, y un Colón que simbolizaría el conocimiento y la sabiduría del Viejo Mundo, atreviéndose a desafiar a la corona española y a los nobles que no se fiaban de su utópico proyecto de llegar a las Indias por otra ruta (Laguna, 2011: 105). Son visiones distintas de lo sucedido, que permiten analizar el imaginario que tienen otros países de lo sucedido. 


\section{Metodología y muestra}

Metodológicamente, para este estudio, se han seguido las siguientes fases: en primer lugar, se ha realizado el visionado de numerosas películas, desde principios del siglo XX hasta hoy, que tratan sobre el encuentro entre los dos mundos, atendiendo a la caracterización o imagen de los conquistadores y exploradores, por un lado, y de las sociedades amerindias, por el otro. En segundo lugar, del total se han seleccionado veintisiete películas (tabla 1) que ofrecían un buen potencial didáctico para la enseñanza de la Historia en Secundaria y Bachillerato. En tercer lugar, derivado de la observación y análisis, hemos llegado a conclusiones que nos han permitido sistematizar el trabajo en unidades de análisis, contrastando los resultados de nuestra investigación con el substrato teórico-crítico de las películas ya existente. Dichas unidades, pensando en formular posibles recursos educativos, se refieren a contenidos espaciales -a través del exotismo de los paisajes americanos-, históricos -el encuentro en sí mismo, si fue violento, curioso, amistoso; en qué medida se refleja una historia impuesta por parte de los vencedores-y ético-morales -los actos de unos y de otros, el interés de unas sociedades en otras, las repercusiones positivas o negativas derivadas del encuentro-. Asumiendo esta última dimensión como la carga emocional y ética señalada por Sánchez Noriega (2008), implícita en el recuerdo del pasado. No se plantea la utilización de estas películas desde el punto de vista de la rigurosidad histórica, al contrario, las cuestionamos desde la consideración de que cualquier producción cinematográfica es producto de una época y unos ideales. Hemos buscado una aproximación a relatos fílmicos distintos, que ofrecen diversas interpretaciones de este contacto. Finalmente, para una mejor utilización de las películas como recurso docente, se han extraído de cada una aquellas secuencias que dan cuenta de las constancias representativas que se canalizan en forma de arquetipos, y acaban convirtiéndose en tópicos y prejuicios que acompañan a la figura del conquistador y la del nativo. Así como realizamos un análisis de las constantes dicotomías que aparecen en las películas que sirven para alejar a la imagen del europeo de la del americano del siglo XVI.

\begin{tabular}{|c|c|c|c|c|c|}
\hline & Película & Dirección & Duración & País & Año \\
\hline \multirow{8}{*}{ 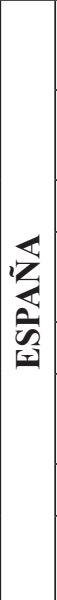 } & Christophe Colomb & $\begin{array}{l}\text { Vincent Lo- } \\
\text { rant-Heilbronn }\end{array}$ & $12 \mathrm{~min}$. & Francia & $\begin{array}{l}1904 \text { cine } \\
\text { mudo }\end{array}$ \\
\hline & $\begin{array}{l}\text { Lavie de Christophe } \\
\text { Colomb }\end{array}$ & $\begin{array}{l}\text { Gérard Bour- } \\
\text { geois }\end{array}$ & $101 \mathrm{~min}$. & $\begin{array}{l}\text { Coproducción } \\
\text { España-Francia }\end{array}$ & $\begin{array}{l}1916 \text { (cine } \\
\text { mudo) }\end{array}$ \\
\hline & Alba de América & Juan de Orduña & $112 \mathrm{~min}$. & España & 1951 \\
\hline & $\begin{array}{l}\text { Los conquistadores del } \\
\text { Pacífico }\end{array}$ & $\begin{array}{l}\text { José María } \\
\text { Elorrieta }\end{array}$ & 96 min. & España & 1963 \\
\hline & El Dorado & Carlos Saura & $142 \mathrm{~min}$. & España & 1988 \\
\hline & $\begin{array}{l}\text { El último viaje del } \\
\text { Almirante }\end{array}$ & $\begin{array}{l}\text { Iván Sáinz-Par- } \\
\text { do }\end{array}$ & $20 \mathrm{~min}$. & España & 2006 \\
\hline & También la lluvia & Icíar Bollaín & $104 \mathrm{~min}$. & España & 2010 \\
\hline & Oro & $\begin{array}{l}\text { Agustín Díaz } \\
\text { Yanes }\end{array}$ & $103 \mathrm{~min}$. & España & 2017 \\
\hline
\end{tabular}




\begin{tabular}{|c|c|c|c|c|c|}
\hline & $\begin{array}{l}\text { La araucana (La con- } \\
\text { quista de Chile) }\end{array}$ & Julio Coll & $100 \mathrm{~min}$. & Chile & 1971 \\
\hline & Nuevo Mundo & Gabriel Retes & $95 \mathrm{~min}$. & México & 1978 \\
\hline & $\begin{array}{l}\text { De la misteriosa Bue- } \\
\text { nos Aires (El hambre) }\end{array}$ & $\begin{array}{l}\text { Alberto Fischer- } \\
\text { man }\end{array}$ & $93 \mathrm{~min}$. & Argentina & 1981 \\
\hline & $\begin{array}{l}\text { Orinoko, Nuevo } \\
\text { Mundo }\end{array}$ & Diego Rísquez & $103 \mathrm{~min}$. & Venezuela & 1984 \\
\hline & Cabeza de Vaca & $\begin{array}{l}\text { Nicolás Echeva- } \\
\text { rría }\end{array}$ & $98 \mathrm{~min}$. & México & 1990 \\
\hline & Jericó & $\begin{array}{l}\text { Luis Alberto } \\
\text { Lamata }\end{array}$ & $90 \mathrm{~min}$. & Venezuela & 1990 \\
\hline & Retorno a Aztlán & $\begin{array}{l}\text { Juan Mora } \\
\text { Catlett }\end{array}$ & 90 min. & México & 1991 \\
\hline & La otra conquista & $\begin{array}{l}\text { Salvador Ca- } \\
\text { rrasco }\end{array}$ & $115 \mathrm{~min}$. & México & 1998 \\
\hline & Eréndira, la indomable & $\begin{array}{l}\text { Juan Mora } \\
\text { Catlett } \\
\end{array}$ & 117 min. & México & 2006 \\
\hline & La carga & Alan Jonsson & $94 \mathrm{~min}$. & México & 2016 \\
\hline \multirow{9}{*}{ 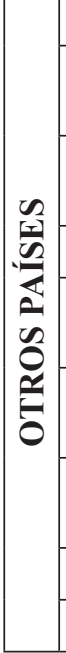 } & Captain from Castile & Henry King & $140 \mathrm{~min}$. & EE.UU. & 1947 \\
\hline & $\begin{array}{l}\text { Aguirre der Zorn } \\
\text { Gottes }\end{array}$ & Werner Herzog & $94 \mathrm{~min}$. & $\begin{array}{l}\text { Alemania del } \\
\text { Oeste (RFA) } \\
\end{array}$ & 1972 \\
\hline & Christopher Columbus & $\begin{array}{l}\text { David MacDo- } \\
\text { nald }\end{array}$ & 99 min. & Reino Unido & 1949 \\
\hline & The Mission & Roland Joffe & $125 \mathrm{~min}$. & Reino Unido & 1986 \\
\hline & $\begin{array}{l}\text { Christopher Columbus: } \\
\text { The Discovery }\end{array}$ & John Glen & $120 \mathrm{~min}$. & EE.UU. & 1992 \\
\hline & \begin{tabular}{|l} 
La controverse de \\
Valladolid \\
\end{tabular} & $\begin{array}{l}\text { Jean-Daniel } \\
\text { Verhaeghe }\end{array}$ & $90 \mathrm{~min}$. & Francia & 1992 \\
\hline & $\begin{array}{l}\text { 1492: The Conquest of } \\
\text { Paradise }\end{array}$ & Ridley Scott & $155 \mathrm{~min}$. & $\begin{array}{l}\text { Reino Unido, } \\
\text { Francia, España }\end{array}$ & 1992 \\
\hline & Carry on Columbus & Gerald Thomas & $91 \mathrm{~min}$. & Reino Unido & 1992 \\
\hline & Apocalypto & Mel Gibson & 136 min. & EE.UU. & 2006 \\
\hline
\end{tabular}

Tabla1. Películas sobre la llegada de Colón a América y el encuentro entre dos mundos, según país y fecha de estreno. [Fuente: elaboración propia] 


\section{Análisis}

\subsection{De lo hostil y lo exótico: América como entorno desconocido}

En todas las películas, América es un paraje exótico tanto en sus gentes, como en su vegetación y fauna. El análisis del espacio que podemos extraer de las películas sobre la llegada de Colón a América nos permite plantearnos desde la educación el análisis de dualidades históricas y espaciales tan dispares como la convivencia en un pueblo nativo o en el campamento de soldados; o fijarnos en las viviendas con la filmación de un palacio español o de un cacique; las armas de los soldados o las armas de los nativos; las intenciones de los dioses amerindios frente a las del dios católico, o las mujeres españolas pudorosas con vestidos pesados frente a las nativas semidesnudas sin ningún pudor.

En algunas películas aparecen soldados que les cuesta adentrarse en el nuevo territorio, que les supera lo desconocido, torpes a la hora de caminar, subir montañas, atravesar selvas tupidas, anchos ríos con fuertes corrientes (López Lizarazo, 2010: 110). Buena muestra de esta torpeza ante una nueva vegetación y territorio se muestra en las primeras escenas de Aguirre, la cólera de Dios (Aguirre der Zorn Gottes, Werner Herzog, 1972) donde se queda atrapada una balsa en un remolino del río, que llevaba parte de la expedición del Perú, sin que otros compañeros pudieran ayudarles -min. dieciséis-. O la imagen tan negativa de los españoles en La otra conquista (Salvador Carrasco, 1998), donde la torpeza de los conquistadores se manifiesta a la hora de recorrer montañas escarpadas con cruces gigantes y esculturas religiosas -min. 11-. Algo similar vemos en La Misión (The Mission, Roland Joffe, 1986), donde el capitán Rodrigo de Mendoza -encarnado por Robert de Niro-, traficante de esclavos, en las proximidades de las cataratas de Iguazú, redime sus pecados atravesando la selva tropical portando una pesada cruz a sus espaldas. La dificultad de su travesía, debido al accidentado terreno, la espesa selva y la altísima humedad, constituyen su verdadera penitencia - min. treinta y dos-. Esta desventaja adaptativa al nuevo entorno se refleja en El Dorado -Carlos Saura, 1988-. Aquí, Lope de Aguirre, miembro de la expedición comandada por Pedro de Ursúa, en 1560, acaba perdiendo la razón ante la monotonía de un paisaje que revelaba la vasta dimensión del nuevo continente. Un río, el Marañón, desde el que sólo se avistaba una densa vegetación, que acrecentaba el imaginario en torno al inalcanzable y mítico El Dorado. Esta influencia del medio que acaba con la salud mental de los españoles se manifiesta igualmente en Alvar Núñez Cabeza de Vaca en Cabeza de Vaca (Nicolás Echeverría, 1990)y en el fraile dominico Santiago en Jericó (Luis Alberto Lamata, 1990).

Otros filmes nos permiten valorar lo exótico a través de los animales que se van encontrando los expedicionarios. Un ejemplo son las escenas de animales exóticos -anacondas, tapires, tucanes- que aparecen en Los conquistadores del Pacifico (José María Elorrieta, 1963) -en el min. veinte-que invitaban al espectador español de los años sesenta, de escasa cultura viajera, a conocer una fauna muy diferente y llamativa. Lo curioso es que se presentan animales de distintos hábitats del centro y sur de América, sin atender a que cada uno proviene de un área geográfica muy distinta. Otro ejemplo de película que transmite las sensaciones de asombro que pudieron tener los exploradores es 1492: La conquista del Paraíso cuando a partir del minuto cincuenta y dos Cristóbal Colón, interpretado por Gérard Depardieu, acompañado por algunos de sus soldados, escuchan y observan distintas especies de serpientes 
y aves que les dejan maravillados por sus llamativos colores. En ese momento se reproducen sonidos de aves y mamíferos de la zona. Es una recreación de un paraíso natural que pudieron identificar los exploradores con la idea del paraíso bíblico.

En un escenario muy distinto, y en los momentos previos a la llegada del europeo a América, Apocalypto (Mel Gibson, 2006), nos muestra a su protagonista, Garra de Jaguar, que debe su supervivencia a la utilización de especies típicas mesoamericanas. Extraeel veneno de una rana, colocándolo en un soplador, deshaciéndose de uno de sus enemigos - min. ciento dieciséis-. Más espectacular es la persecución de un jaguar, del que finalmente consigue zafarse provocando su ataque a otro de sus perseguidores - min. noventa y cinco-.

\subsection{Interés excesivo o nulo en la vida cotidiana de los nativos}

Si quisiéramos que los estudiantes empatizaran históricamente con las culturas prehispánicas, que hicieran un análisis reflexivo sobre cómo vieron al extranjero y cómo se pudieron sentir en el encuentro, cabría buscar a protagonistas nativos en la filmografía. Sin embargo, pocas son las películas sobre el encuentro que tienen como protagonista a un nativo o nativa, con excepción de la leyenda de Eréndida, la indomable (Eréndida Ikikunari, Juan Mora Catlett, 2006). Eréndida es una joven india purépecha, que luchó frente a los españoles y las facciones de su propio pueblo que les apoyaron, con el fin de mantener intacta la identidad de su cultura.

Encontramos una visión más completa de la forma de vida de los nativos en películas que traten del momento previo a la llegada de Colón: es el caso de Retorno a Aztlán (Juan Mora Catlett, 1991) grabada en náhuatl, lengua mexica, que narra las aventuras de un guerrero que se marcha a Aztlán con mantas, cacao, maíz, para pedir a la diosa madre que restablezca la lluvia por la sequía que estaban padeciendo. Permite trabajar actividades sobre el comportamiento nativo, su jerarquización, el papel de los chamanes, y el dominio de los mexicas sobre el resto de las culturas adyacentes.

De nuevo Apocalypto nos ofrece un buen ejemplo, aunque existen elementos discutibles en esta superproducción, como el desfase cronológico respecto al contexto en el que se desarrolla la acción y el verdadero declive de la cultura postclásica maya. Sin embargo, destaca la presentación del ritual de sacrificios humanos, acercándonos por una parte al simbolismo cinegético y agrario entre los mayas del postclásico, como consecuencia de malas cosechas y plagas - min. setenta y tres(Morales-Damián y Domínguez-Ángeles, 2019); y por otra a las dramáticas escenas de extracción del corazón del prisionero en vida, recogidas por cronistas como el franciscano Diego de Landa (2017) o el Códice Dresde (Tiesler y Cucina, 2007). Destacan también en estas escenas de sacrificios la parafernalia ceremonial a través de espléndidas reproducciones de tocados, penachos de plumas, narigueras, bezotes, máscaras, cuchillos de obsidiana y demás adornos de jade (min. setenta y dos). La decoración corporal muestra perforaciones, escarificaciones y pintura. Las escenas de vida cotidiana - min. dieciséis- en la pequeña aldea de Garra de Jaguar, presentan juegos infantiles y ceremonias en torno al fuego en las que los ancianos narran leyendas de sus antepasados. Acusan sin embargo cierta homogenización y mitificación del mundo mesoamericano.

Otro ejemplo, pero este sí trata del resultado de la convivencia con españoles es La otra conquista que narra la historia de Topiltzin, un superviviente del Imperio 
Mexica que se resiste al dominio español. La película se ambienta en la época en que Hernán Cortés estaba con Isabel Moctezuma, y muestra el sometimiento y aculturación obligada de los mexicas. Con una imagen de los conquistadores españoles muy negativa, se pueden ver escenas muy significativas de la ruina del imperio, como los restos destruidos de templos y pirámides (min. siete). En este filme el uso de muchos actores de acento mexicano para los papeles de soldados y conquistadores españoles desvirtúa un poco la historia, no obstante, ocurre lo mismo cuando en distintas películas aparecen nativos que chapurrean o hablan perfectamente español, desde el inicio del encuentro.

Para poder conocer de manera fiable la cotidianeidad de los nativos es preciso acudir a las películas producidas en Hispanoamérica: un buen ejemplo es el filme Orinoko, Nuevo Mundo (Diego Rísquez, 1984),que toma como hilo conductor al río Orinoco y lo que ocurre en él a lo largo de los siglos; al menos hasta el minuto dieciocho en que aparece la figura de Colón, el filme es un canto a la felicidad del nativo previa a la conquista. Es una película sin diálogos donde aparecen escenas bien documentadas sobre caza, pesca, juegos infantiles, y costumbres de los chamanes, con sonidos y música de fondo, que sitúan al espectador en plena cuenca del Orinoco. Sobre esta vida cotidiana, nos ofrece información muy útil Cabeza de Vaca, que aproxima al alumnado a otras realidades culturales fomentando el relativismo cultural en las aulas. Aquí, el tesorero de Carlos I, Alvar Núñez Cabeza de Vaca, acaba siendo apresado por un grupo de indígenas tras naufragar la embarcación comandada por Pánfilo de Narváez. Cabeza de Vaca es llevado a una comunidad india, en la que se aprecian adornos de arte plumario, viviendas de tipo palafitos, adornos e instrumentos musicales, canoas -min. diecinueve-. Además, muestran modos de subsistencia tradicionales de pueblos prehispánicos como la recolección de moluscos o la pesca. El protagonista es esclavizado, rasgo distintivo de algunas de estas comunidades también, y será liberado al convertirse en chamán, tras adquirir dotes como curandero después de ser drogado con una sustancia alucinógena.

Un elemento frecuente es la música como intermediador entre ambas realidades. La Misión es un claro ejemplo, cuando en el minuto diez aproximadamente, el padre Gabriel -Jeremy Irons- entra en contacto con un grupo nativo precisamente tocando un oboe, cuyo sonido logra cautivar a los indios.

Destacaremos aquí, por ser interesante de cara al alumnado, algunas películas que no ponen ningún cuidado en la representación del nativo: una de las más destacadas es Los conquistadores del Pacifico, en la que los indígenas hablan español, y muchos de ellos, tienen un físico caucásico. Sus vestimentas recuerdan más a los indios de Norteamérica -min. veinticinco aprox.-, y sus casas erróneamente tienen aspecto de cabaña europea con ventanas, puertas, y decoradas interiormente con cojines y cortinas.

Esta falta de interés en la realidad del indio es patente también en El Capitán de Castilla (Captain from Castile, Henry King, 1947), producto de esa mirada por encima del hombro hacia otras culturas, resultando en una sucesión de estereotipos hacia los mexicas que reciben a Hernán Cortés. Pedro de Vargas, capitán de Castilla, asiste a la entrega de presentes que los indios ofrecen a los recién llegados en nombre de Moctezuma. Se presenta a los indígenas desde una imagen paternalista, propia de los años cuarenta en Estados Unidos, despojándoles de su capacidad para decidir su propio destino. Son indios vestidos, barbudos, cuya parafernalia está alejada de la realidad en cuanto a diseños o materiales. Su arte plumario no refleja la grandeza de 
los tocados indígenas, con la excepción del que porta el embajador real de Moctezuma -min. noventa y nueve-, poco logrado por otra parte. La representación de las pirámides, frescos de los templos, y esculturas que adornan ambos, nada tienen que ver con la iconografía azteca.

\subsection{La figura del conquistador: héroes o codiciosos de oro}

Aunque parece obvio que el metal dorado mueve la ambición de los españoles en la mayoría de las películas, justificando toda barbarie por conseguirlo, también ocurre lo contrario, con películas que minimizan el valor del oro en la conquista. Para ello se enfatiza la misión civilizadora y "avance tecnológico" que aportan los extranjeros a los nativos.

Las películas extranjeras, de habla no hispana, ofrecen una imagen de la obsesión de los españoles por encontrar el oro y alcanzar El Dorado: una codicia que acaba derivando en una continua traición de un grupo de españoles frente a otros; traición entre iguales, otras veces contra la autoridad del capitán o el mando de la expedición, y otras incluso contra la propia corona española. Sin duda, la película más bizarra en este sentido es Aguirre, la cólera de Dios que es una crítica al papel de los conquistadores que se traicionan continuamente. Menos surrealista, pero con el oro como protagonista de fondo, está el filme Cristóbal Colón: el descubrimiento. Y más amable con el papel de Cristóbal Colón que aparece idealizado como pacificador e interesado en el bien de los nativos (España, 1992) está 1492: La conquista del Paraíso, no obstante, Colón acaba siendo incapaz de poner orden a la avaricia de sus hombres ante el inalcanzable oro.

Las películas españolas muestran un antes y un después con la conmemoración del V Centenario del descubrimiento en 1992 (Stam, 1993). Anteriores a esta fecha, debemos retrotraernos a las décadas de los cincuenta y sesenta, donde la conquista de América es utilizada por el franquismo para realzar el pasado glorioso. Estas películas daban alas a soñar con volver a ser una nación en expansión. Destacan unos conquistadores que son héroes a los que no les importa nada el oro, sino llevar la cultura y el avance técnico y urbanístico a los "salvajes y primitivos". Un ejemplo es Los conquistadores del Pacífico que muestra a un Núñez de Balboa que regala la construcción de casas e iglesias al estilo castellano a los nativos.

A partir de finales de los años ochenta vemos un cambio de tendencia en el tratamiento del conquistador: estos comienzan a ser reconocidos como codiciosos, crueles, y deshumanizados, a quienes les importa tan poco la vida del indio como la de sus propios compañeros. En El Dorado, Lope de Aguirre promueve varias revueltas para conseguir el poder con el fin de alcanzar El Dorado. Esta misma codicia es protagonista del tormentoso final que afronta Colón en el cortometraje El último viaje del Almirante (Iván Sáinz-Pardo, 2006) quien, en su lecho de muerte, en Valladolid, reconoce ante sus hijos la fiebre del oro que causó su empresa en América -min. cuatro-.

Continuadora de esta transformación es Oro (Agustín Díaz Yanes, 2017), que muestra a unos conquistadores capaces de matarse entre compañeros por el ansiado metal. En esta línea, encontramos ejemplos de películas hispanoamericanas. El caso más delirante es De la misteriosa Buenos Aires (Alberto Fischerman, 1981), en la que la primera historieta, titulada "El hambre", realiza un retrato muy duro del comportamiento de los conquistadores que en algunas zonas buscaban el oro y se 
encontraron con la miseria y el hambre. Una imagen lamentable de la conquista del sur de América, alejada de discursos triunfalistas, que acaba en la mayor degradación del conquistador; el uso del canibalismo entre los españoles, que tanto habían criticado - min. veinticuatro-. Ésta la encontramos también en Jericó, donde el cruel conquistador Gazcuña acaba practicando canibalismo -min. treinta y uno-.

\subsection{El momento del encuentro: nativos sometidos, curiosos o combativos}

Centrándonos en el momento del primer contacto y sus reacciones, atendiendo a la mirada del director de la película, se podría analizar con los estudiantes las distintas interpretaciones: en primer lugar, visualizar las escenas de películas con nativos que salen de la selva con seguridad a recibir con honores y alegría a los recién llegados, advirtiendo amistad y entusiasmo; tanto es así que los españoles son considerados dioses. Destacan la francesa muda Christophe Colomb (Vincent Lorant-Heilbronn, 1904) y la coproducción franco-española, también muda, La vida de Cristóbal Colón y su descubrimiento de América (La vie de Christophe Colomb, Gérard Bourgeois, 1916).

Las dos aportan una gran falta de rigor histórico (Laguna, 2011: 102): la primera y más antigua, por mostrar en el momento del desembarco de Colón a unos indígenas con plumas y flores que reciben con gran júbilo la llegada y agasajan a los navegantes bailando al estilo hawaiano - min. tres-, y la segunda por mostrar a cientos de soldados españoles que acompañaban a Colón a caballo, y a unos nativos que van a su encuentro con gran alegría, bailes, y automáticamente se postran para mostrar su sometimiento - min. cincuenta y siete-. Esta línea es la que defiende a kilómetros de distancia, en Valladolid, De las Casas frente a Sepúlveda en La Controverse de Valladolid (Jean Daniel Verhaeghe, 1992): reunida la Junta en 1550, sirvió de escenario para debatir sobre la naturaleza de los indígenas; De las Casas defendía su naturaleza humana, sensibilidad artística, emocional y costumbres. Afirma que recibían con los brazos abiertos e inocencia a los recién llegados, los mismos que con despiadada crueldad los torturaban, mutilaban y destruían su cultura.

En segundo lugar, se podrían analizar películas en las que la imagen de los nativos es de pura curiosidad: salen de la selva hacia la playa con cierto temor a recibir a los españoles, pero, rápidamente, se acercan a investigar los rostros, vestimentas y armaduras de los extranjeros. Es el caso de Cristóbal Colón: el descubrimiento que muestra la gran curiosidad de unos con otros con respecto al físico y la vestimenta -min. ochenta y tres-, no obstante, poco dura el interés porque a los pocos minutos del encuentro los españoles se dan cuenta de que los nativos tienen oro en su ornamentación personal, y la codicia da comienzo al sometimiento. Otra película que ofrece seguramente la visión más amable del encuentro es 1492: La conquista del Paraíso cuando aparecen los nativos en plena selva y rodean a los españoles con curiosidad; les tocan las barbas, los cascos, armaduras, y hasta les conducen hasta el poblado con gran asombro, convirtiendo a los españoles en los exóticos y extraños -min. cincuenta y cuatro-, y no al revés como acostumbran a mostrar la mayoría de las películas desde la perspectiva del europeo.

En tercer lugar, se podrían analizar secuencias que ofrecen la imagen de unos nativos agresivos que disparan flechas desde el primer contacto visual con los españoles, lo que va a justificar todo acto "poco ético" de los soldados a partir de entonces; es, por tanto, un choque brutal, que rompe con el interés de unos hacia otros, y que da 
comienzo a una relación injusta de sometimiento. En este sentido, destaca Los conquistadores del Pacifico en el que el encuentro es violento por culpa de los nativos que lanzan flechas a los españoles, quienes no dudan en matarlos para defenderse. Y por supuesto, mostrando siempre la superioridad de los conquistadores que vencen fácilmente a los nativos por el uso de armas de fuego frente a las flechas indígenas, y por el dominio en altura de los conquistadores que van a caballo ante unos débiles nativos que van a pie - min. veintiuno-.

La mexicana Nuevo Mundo (Gabriel Retes, 1978), conjuga la visión histórica con el ya tradicional arraigado odio a lo español del criollismo (González, 2015: 55-56). Fue una película polémica debido al cuestionamiento de la Virgen de Guadalupe: los españoles aparecen como crueles, y un sacerdote jesuita inventa la presencia de una virgen que intercede para la reconciliación entre conquistadores y conquistados; los sacerdotes intentan frenar lo que parece una revuelta indígena, auspiciada por el encomendero don Diego, arrepentido por su pasado en el que asesinó a numerosos indios.

\section{Conclusión}

El cine, considerado como documento histórico en tanto no sólo a lo que dice u omite, sino como reflejo de la época que lo produce, aporta numerosos beneficios en el tratamiento didáctico del descubrimiento de América: algunas de las razones serían la capacidad motivadora, evocadora, y el fomento de las competencias sociales, cívicas, y de expresiones culturales, a través del pensamiento crítico y creativo; todo ello se enriquece si es introducido en su contexto adecuadamente por el docente, y se aborda como una realidad cambiante, desde una mirada plural, y atendiendo a sensibilidades distintas, empleando la empatía histórica.

Todo ello, debe entrenarse desde la etapa de Educación Primaria. Además, el cine y su visionado, seleccionando diferentes puntos de vista en torno a este capítulo histórico, puede contribuir a alcanzar los objetivos curriculares en el primer ciclo de la ESO en cuanto a contenidos sobre la conquista y colonización de América (RD 1105/2014: 300); los criterios de evaluación en cuanto al entendimiento de los procesos de conquista y colonización y sus consecuencias; y finalmente en cuanto a estándares de aprendizaje, al sopesar interpretaciones conflictivas sobre la conquista y colonización de América. También en segundo de Bachillerato, cuando los estándares de aprendizaje proponen: "analizar la política respecto a América en el s. XVI y sus consecuencias para España, Europa y la población americana" (RD 1105/2014: $323)$.

Hemos analizado veintisiete películas que contextualizan este hecho histórico; todas ellas ofrecen un análisis fruto de la época en la que fueron realizadas. A través de fragmentos, cuidadosamente seleccionados, proponemos su uso en el aula para abordar el conocimiento de América desde planteamientos conceptuales innovadores propios de las Ciencias Sociales, que permitan fomentar la educación cinematográfica del alumnado.

Concluimos destacando el empleo del cine histórico para contextualizar el encuentro, como forma de entender problemas actuales mirando al pasado. También la lluvia (Icíar Bollaín, 2010) ofrece un escenario de acción didáctica: aquí, la decisión de privatizar un bien de primera necesidad como es el agua en el presente, en la ac- 
tual Bolivia, confluye con el rodaje de una película española sobre la conquista. En torno a ambas injusticias, se tejen relaciones en las que pasado y presente se unen en una misma realidad (Dávila, 2017). Ello nos permite vincular el conflicto social con el hecho histórico (Lorente, 2019), el pasado y el presente, a través del cine.

\section{Bibliografía}

Bueno Jiménez, A. (2019). "Cristóbal Colón y el hallazgo de América a través del cine”. Cuadernos Americanos, vol. 168, núm. 2, 89-119.

Burke, P. (2001). Visto y no visto. El uso y la imagen como documento histórico. Barcelona: Crítica.

Burman, C. (2006). "Cristóbal Colón en Cine". Actas del XVII Coloquio de Historia Canario-Americana. Las Palmas: Cabildo Insular, pp. 753-759.

Dávila Vargas-Machuca, M. (2017). “Cine dentro del cine. Historia dentro de la historia: También la lluvia (Icíar Bollaín, 2010)”. Procesos históricos. Revista de Historia y Ciencias Sociales, 31, pp. 168-184.

Deltell Escolar, L (2006). Madrid en el cine de la década de los cincuenta. Madrid: Ayuntamiento de Madrid.

Doñate, O. y Ferrete, C. (2019). "Vivir la historia. Posibilidades de la empatía histórica para motivar al alumnado y lograr una comprensión efectiva de los hechos históricos”. Didáctica de las Ciencias Experimentales y Sociales, vol. 36, 47-60.

España Renedo, R. (1992). "España y América: 500 años de Historia a través del Cine", Filmhistoria online, vol. 2, núm. 3,189-219.

Ferro, M. (1980). Cine e historia. Col. Punto y Línea. Barcelona: Gustavo Gili.

Ferro, M. (1995). Historia contemporánea y cine. Barcelona: Ariel.

García Fernández, E. C. (Coord.) (2011). Historia del cine. Madrid: Fragua.

González Manrique, M. J. (2015). "La imagen del clero en el cine de conquista mexicana. La Leyenda Negra en el Nuevo Mundo de Gabriel Retes". Boletín americanista, vol. 2, núm. 71, 55-76.

Gorgues, R., Enguix, R. y Goberna, J. J. (1997). "El cine en la clase de Historia: un proyecto didáctico para la ESO y Bachillerato". Íber, vol. 11, 71-78.

Juan-Navarro, S. (2008). "De los orígenes del estado español al nuevo estado: la construcción de la ideología franquista en Alba de América, de Juan de Orduña”. Anales de la Literatura Española Contemporánea, vol. 22, núm. 1, 74-104.

Landa, D. (2017). Relación de las cosas de Yucatán. Madrid: Alianza.

López Lizarazo, C.A. (2010). "Lo exótico en el cine sobre la conquista de América". Anagramas, vol. 8, núm. 16, 105-116.

Lorente, N. (2019). "Retóricas y estéticas del descubrimiento de América en También la lluvia (2010), de Icíar Bollaín”. Quaderns, vol. 14, 21-31.

Manzi, I. (2006). "Cristóbal Colón visto por el cine". Cuadernos Hispanoamericanos, vol. $677,113-121$.

Martínez, F. (2013). “La historia y el cine ¿unas amistades peligrosas?”.Vinculos de historia, vol. 2, 351-372).

Mora, J. (2014). "El Dorado: tras la leyenda que forjó América". Clío: Revista de Historia, vol. $147,40-47$.

Mora, C. J. (2004). Mexican Cinema. Reflections of a Society (1896-1988). Berkeley: California University Press. 
Morales-Damián, M.A. y Domínguez-Ángeles, A. (2019). "Simbolismo cinegético y agrario de los sacrificios guerreros entre los mayas de Yucatán durante el Postclásico". Liminar. Estudios sociales y humanísticos, vol. 17, núm. 2, 98-114.

Pérez Cipitria, A. (2010). "El cine histórico de Juan de Orduña y el franquismo". Revista de Claseshistoria, vol. 66. Recuperado de: http:/www.claseshistoria.com/revista/2010/ articulos/perez-orduna-cine.pdf

Pérez Vejo, T. (2016). "Naciones y nacionalismo en las independencias hispanoamericanas: una revisión historiográfica”. Ayer, vol. 103, núm. 3, 199-210.

Rosenstone, R. (1995). "The historical film, as real history". Filmhistoria, vol 5, núm. 1. Recuperado de: https://revistes.ub.edu/index.php/filmhistoria/article/view/12244/14998

Sánchez Noriega, J.L. (2008). "De la película histórica al cine de memoria”. En G. Camarero, B. de las Heras y V. de Cruz (eds.), Una ventana indiscreta. La Historia desde el cine. Madrid: Universidad Carlos III de Madrid, Instituto de Cultura y Tecnología, Cátedra de Estudios Portugueses Luís de Camoes, pp. 19-32.

Santisteban Fernández, A. (2019). "La enseñanza de las Ciencias Sociales a partir de problemas sociales o temas controvertidos: estado de la cuestión y resultados de una investigación”. El Futuro del Pasado, vol. 10, 57-79.

Solá, A. y Selva, M. (1997). "Reflexiones alrededor del cine y la historia en la enseñanza". Íber, vol. 11, 71-78.

Sorlin, P. (2008). “Cine e historia. Una relación que hay que repensar". En G. Camarero, B. de las Heras y V. de Cruz), Una ventana indiscreta. La Historia desde el cine. Madrid: Universidad Carlos III de Madrid, Instituto de Cultura y Tecnología, Cátedra de Estudios Portugueses "Luís de Camoes", pp. 19-32.

Stam, R. (1993). "Rewriting 1492: Cinema and the Columbus Debate". Cinéaste, vol. 19, núm. 4, 66-71. Recuperado de: http://www.jstor.org/stable/41687250

Tiesler, V. y Cucina, A. (2007). "El sacrificio humano por extracción del corazón. Una evaluación osteotafonómica de violencia ritual entre los mayas del Clásico". Estudios de cultura maya, vol. 30, núm. 1. 